Another area of discussion was how management training should best be provided; at a local level, in an experiential manner with skilled and successful consultants as role models or with sympathetic and educationally minded managers; or on specialist management courses for psychiatrists.
Both were considered essential and great concern was therefore expressed over the increasing difficulties in obtaining funds for psychiatric trainees to attend formal courses; a surprising development when the 'consultant as manager' is being so widely encouraged.

\title{
Statement on abuse and harassment within psychiatric hospitals
}

Incidents involving sexual harassment of patients in psychiatric hospitals have been brought to the notice of the Public Policy Committee. Sexual abuse and harassment may be seen in the context of more general misuse and exploitation of patients by other patients or members of staff or intruders. These incidents vary from kerb crawling by intruders within hospital grounds to sexual exploitation of weaker or less able patients by those capable of wielding more power. Managers should be responsible for maintaining the safety of hospital grounds from intruders.

Particularly vulnerable are adolescents with psychosis who are in adult wards and the more mentally handicapped patients who are at risk from those who are mildly handicapped. Where there is a clear difference in the amount of power possessed by the two involved, steps must be taken to protect the interests of the weaker ones, especially when there can be no question of valid consent. Difficult issues arise when there is only partial consent or when both parties have formed a strong attachment to each other in conditions of somewhat restricted lives. Such occasions can occur in secure units, in long-term mental handicap hospitals or continuing care wards catering for the elderly mentally infirm.

These problems are best tackled by education. Sexual education and counselling aimed at increasing awareness of self, personal boundaries and the right to make decisions about one's own body are appropriate for younger or mentally handicapped patients. Contraception advice should be available but must always be accompanied by counselling. Training of staff should include appreciation of the social, emotional and sexual needs of patients.

Dr A. GatH June 1989

\section{New publication}

\section{Basic Sciences}

The BASIC SCIENCES Reading List for trainees, produced by the Library, is now available from the College, price $£ 1$.

SUSAN FLOATE

Librarian 